\title{
La luna y la feminidad entre los tobas del oeste formoseño (Gran Chaco, Argentina)'
}

Cecilia Paula Gómez

Campos 11(1): 47-64, 2010.

\section{PLANTEAMIENTO DEL PROBLEMA}

El análisis antropológico de las concepciones astronómicas chaqueñas revela una serie de relaciones significativas entre determinados ritmos fisiológicos asociados con la feminidad y los períodos de tiempo que suelen marcarse por medio de representaciones asociadas con la luna ${ }^{2}$. En este sentido, un fenómeno particularmente interesante es el armazón simbólico y social que presta sentido a la concepción de la feminidad, y en particular a las relaciones entre el universo femenino y el plano de lo celeste entre los tobas del Oeste formoseño. Como ha advertido Lévi-Strauss (1997), la estrecha relación entre los períodos femeninos y los ritmos cósmicos hace que una insubordinación femenina frente a las reglas sociales pueda provocar importantes problemas tanto a nivel social como a nivel cosmológico. En el caso de los tobas, estas catástrofes pueden afectar tanto a la mujer que no se ajusta a las reglas como a su entorno familiar o incluso al poblado en general. No es extraño, entonces, que un análisis de las concepciones tobas del plano celeste evoque recurrentemente el carácter liminal y a la vez peligroso de las mujeres. Problematizada explícitamente en su origen mítico, dicha liminaridad se manifiesta con claridad en algunas etapas de su vida, de las cuales analizaremos una en particular: el momento en que las muchachas se transforman en mujeres socialmente casaderas. Por medio de la luna y su relación con los ciclos menstruales se enlazan diversos significados simbólicos que dan cuenta de la relación mítica de las mujeres con el plano celeste. La asociación con Luna vuelve a relacionar periódicamente a las mujeres con el cielo, y a la vez evoca el momento mítico de su "domesticación", llevada a cabo por el trickster wayaka' lachigi, el zorro, responsable de que las mujeres dejaran de tener dientes en sus vaginas y pudieran entonces permanecer con los hombres en calidad de esposas y madres. Sólo luego de ese pasaje inmemorial las mujeres "pre-sociales" podrán cumplir con su rol social. 
Sin embargo, antes de comenzar a plantear el problema es necesario ubicar brevemente a los tobas dentro del conjunto de los pueblos chaqueños. De forma general puede decirse que entre los grupos étnicos chaqueños los tobas forman parte de los grupos "chaqueños centrales" o "chaqueños típicos" (Braunstein 2008: 20-21). Las sociedades que conforman este conglomerado ocupan las cuencas de los ríos Pilcomayo y Bermejo, y conforman uno de los tres grandes conjuntos de pueblos que pueden distinguirse analíticamente entre los indígenas del Gran $\mathrm{Chaco}^{3}$. La economía de estos grupos tradicionalmente se ha basado en la caza, la pesca, la recolección y la práctica de una agricultura rudimentaria; en términos arqueológicos, podríamos decir que se trata de "cazadores recolectores complejos".

Los tobas que habitan el oeste de la provincia de Formosa residen específicamente en el Departamento Bermejo, a aproximadamente ochenta kilómetros de la ciudad de Ingeniero Juárez. En la literatura, este grupo también ha sido Ilamado "toba-pilagá", "tobas del Pilcomayo medio", "tobas de Sombrero Negro" y "tobas ñachilamole'k" (Métraux 1937; Arenas 2003). De aquí en más, salvo que se especifique lo contrario, se estará haciendo referencia a esta parcialidad específica cuando se escriba "toba". Los asentamientos en los que vive esta gente son varios, siendo Vaca Perdida, La Rinconada y El Churcal los más poblados. También existen otros más pequeños como La Mocha, Seis de Abril, Tres Yuchanes, Pozo Ramón, Isla García, La Madrugada, Pozo Charata, El Breal, La Bolsa, Laguna Cansino, Quebrachito o Barrio Méndez. Finalmente, hay un número importante de asentamientos estacionales (Córdoba 2008a: 133) ${ }^{4}$. Según el censo realizado en 1999 por la Asociación Civil Comlaje'pi naleua, los tobas son aproximadamente unas 2000 personas. Durante 1989, esta gente accedió a la propiedad de un territorio de 35.000 hectáreas que incluye a parte de sus circuitos tradicionales de caza, pesca y recolección (Gordillo 2005: 204; Córdoba 2008a: 135).

Mi trabajo de campo entre los tobas incluyó varias campañas de campo entre 2006 y 2009, orientadas explícitamente a documentar las percepciones nativas del cielo en distintos momentos del ciclo anual. En este sentido, fue realizado un trabajo de seguimiento progresivo de la observación nativa del cielo nocturno durante diversos períodos estacionales, con el fin de obtener un panorama integral que tomara en cuenta la variabilidad de la percepción nocturna del plano celeste: en efecto, para los tobas hay momentos "diagnósticos" en los cuales afirman que resulta interesante observar el cielo, y otros momentos etno-astronómicamente "neutros", en los cuales simplemente dicen que la tarea es más difícil o bien que carece de interés porque "el cielo está más lejos", porque "no se ve bien", etc. La investigación de campo se desarrolló en varias comunidades aunque la mayoría de los datos fue recogida en la comunidad de Vaca Perdida por medio de observación participante, entrevistas abiertas, encuestas semi-estructuradas y la posterior triangulación de los datos recabados. Metodológicamente, la investigación procuró en todo momento combinar la aprehensión etnográfica de las percepciones tobas del plano celeste con un conocimiento básico de astronomía de posición y la familiarización progresiva con la lengua nativa, a fin de recabar textos en idioma nativo. 


\section{LUNA NACIENDO Y MURIENDO: LAS FASES LUNARES}

Alfred Métraux (1946: 16) escribía que los cuerpos celestes, al igual que algunos fenómenos naturales, son personificados y considerados por los tobas como serviciales o peligrosos; sin embargo, insiste en que no hay evidencia concreta que indique la realización de cultos regulares en torno a ellos. En el mismo libro, sin embargo, nota que "cuando la luna palidece, la gente dice que ella está muriendo o que se va a cazar. Cuando la luna reaparece, ellos la saludan y preguntan: ¿Cómo estás tú? ¿Has tenido un buen viaje? Hombres y mujeres se regocijan porque pronto podrán bailar por la noche. Según su forma la luna cambia su posición. Eso es porque la luna es un hombre cansando que no puede echarse mucho tiempo del mismo lado" (1946: 19)5. Según el etnógrafo suizo se considera que la luna muere y que es un ser masculino, afirmaciones que no son contradictorias con lo relatado actualmente por los tobas. Inclusive hoy en día las mujeres tienen muy presente a la luna a nivel tanto simbólico como práctico, pues les sirve para realizar mediciones de diversos ciclos fisiológicos y temporales. Las fases de la luna hablan de un desarrollo particular. No hay un término exacto para designar cada una de ellas; sin embargo, salvo que hagan una traducción del término en castellano, en general se las describe como si se refirieran al ciclo vital de un ser vivo: es precisamente por eso que se considera que Luna "no es como las estrellas", pues cumple con etapas del ciclo vital. Por ejemplo, la luna muere: cuando "la luna se va", se la considera $i^{\prime}$ lew ("muerto"). Los ancianos también afirman que luego de esa desaparición la luna resurge: "A'wogoyk (luna) se murió. Pero los ancianos decían que iba a volver todos los meses. (...) luego vuelve jovencita". Por otra parte se reconoce que Luna tiene ado'wa (esposa), una estrella cercana.

La explicación sobre Luna y su aparente movimiento en la bóveda celeste ${ }^{6}$ remite a un conjunto de ideas que evocan la juventud, la madurez y la muerte de un ser vivo, un ser que desaparece pero vuelve a aparecer. Unos de los ancianos, así, afirma que Luna nueva es "hijo" de aquel que anteriormente había desaparecido. Cuando Luna es joven se le puede llamar a'wogoyk dalaichi (luna tierna) ka'leka, kat'ñwk (muy pequeño) o 'dalagaik (nuevo/ tierno). También se recogió un término más complejo pero interesante, teyagaiki (lit. "mira hacia los chulupí o nivaclé"), puesto que la parte cóncava de esta fase lunar da hacia el norte, en donde habita ese grupo étnico, que era tradicionalmente el enemigo preferencial de los tobas. Los términos transcriptos remiten al primer cuarto del ciclo de las fases lunares, sobre todo a la primera visibilidad del cuarto creciente. Cada vez que se hablaba del tema con los tobas, la referencia más inmediata era señalar hacia el cielo y explicar en qué lugar aparece la luna cuando se la describe como "tierna", "pequeña" o "nuevita"; por ello se hace referencia a su aparición hacia el oeste de la bóveda celeste y cómo desaparece en poco tiempo hacia el poniente. En otras palabras: la figura que tiene la luna en cada una de sus fases es leída en conjunto con su posicionamiento en el cielo, siendo este último el marcador más inmediato. Con respecto a la luna llena, es descripta con términos como a'vik 'taraik (muy maduro), taa'ñi (duro), a'wogoyk yono (luna llena/completa), nalota (completo). Cuando se hace referencia al tercer cuarto del ciclo de fases se dice yagai' $k i$ (anciano/viejo); y cuando se llega al final de este período, el cuarto menguante, se la llama yi'lew (muerto), ilew (muere), to'yek (se va), ek (se va). Para finalizar, la ausencia 
de la luna, o luna nueva, se denomina simplemente kai'ak a'wogoyk (no hay luna, sin luna).

Asimismo, el término a'wogoyk indica el ciclo en el cual Luna realiza su recorrido en dirección de oeste a este, desaparece por un tiempo y surge nuevamente por el oeste. Es por ello que, en los léxicos, la traducción de a'wogoyk es tanto "luna" como "mes". Según observaba Miguel?: "[Cuando aparecía] luna nueva era el primer, o segundo, o tercer día del mes [nuevo], cuando ellos no tenían fecha, pero ellos [los ancianos] lo sabían. Cuando la luna muere es cuando no está y ya se termina el mes". Lo expresado corresponde acertadamente a aquello que se denomina "mes sinódico", es decir, el intervalo de tiempo que transcurre entre, por ejemplo, dos cuartos crecientes, o bien lo que el entrevistado llama "luna nueva". Naturalmente esto implica un ciclo completo de fases, lo que dura algo más de cuatro semanas (el mes sinódico dura 29,5 días aproximadamente). Estas mediciones ya habían sido descriptas por los expedicionarios que estuvieron por la zona a principios del siglo XX: por ejemplo, Erland Nordenskiöld (2002: 48), refiriéndose a los vecinos chorote y chulupí (nivaclé) del río Pilcomayo, explica que la luna era utilizada para determinar períodos más cortos que las estaciones.

Los tobas contemporáneos subrayan que a la luna se le presta especial importancia porque por su intermedio las mujeres saben cuándo tendrán su próxima menstruación, si quedaron embarazadas o bien cuánto falta para el nacimiento de su hijo. Se impone entonces indagar en la simbología lunar: qué significa ese personaje celeste masculino que nace y envejece, que "tiene trabajo en la tierra" y que opera como un marcador temporal ineludible.

\section{LUNA, TIEMPO Y MUJER}

En la etnografía realizada en 1912 por Rafael Karsten (1923: 26) entre los tobas bolivianos, se indica que los indígenas pensaban que la menstruación era causada o influenciada por la luna. Entre los tobas del Oeste formoseño, la relación entre luna y la sexualidad femenina parece, igualmente, bastante evidente. Métraux también hizo referencia a ese vínculo en sus clásicos estudios sobre la mitología toba y pilagá, indicando que "cuando el hígado de una mujer exuda sangre (i.e. cuando ella menstrúa), algunas personas dicen que ella ha tenido relaciones sexuales con Luna". Asimismo, explica que Luna es considerado como un hombre barrigón, cuyos intestinos azulados pueden ser vistos a través de su piel (1946: 19)

El mito de las relaciones sexuales entre Luna y las mujeres que tienen su primera menstruación puede todavía escucharse entre los tobas; de hecho, las madres les dicen a las jovencitas, cuando acontece su menarca, que "Luna la provocó"9. A ello se agrega, seguramente, el hecho de que la fase lunar en la que tuvo su período por primera vez será la misma cuando acontezcan las próximas menstruaciones. La posición de la luna en el cielo y la figura que forme, entonces, marcará el período menstrual de cada mujer: “Las mujeres cuando sale la menstruación saben por la altura de la luna". Así es que las jóvenes tobas comienzan a prestarle atención a la forma y el movimiento que la luna parece describir en el cielo. Una de las mujeres comentaba que su primera menstruación fue con ya' $k a c h i^{10} a^{\prime}$ woGoyk (lit. "luna muy viejo"), y que actualmente tiene su período en ese preciso momento. Sin embargo, en ese testimonio no sólo se indicaba que la muchacha tendrá su período siempre con 
"a'wogoyk ya'kachi" (lit. "luna muy viejo"), sino que sugiere que tendrá un esposo mayor, o incluso que puede llegar a no tenerlo. De cualquier forma, la misma mujer dice a continuación: “Es la historia de ellos, yo casi no creo, porque yo siempre hasta ahora encuentro novio". Poco a poco, en efecto, las mujeres jóvenes comienzan a marcar cierta distancia con el "conocimiento de ellos", aunque aún lo comparten como un saber básico que deben aprender las mujeres. Estos conocimientos son de dominio tanto femenino como masculino: en un matrimonio, el marido sabe perfectamente "cuál es la luna de su mujer", y también, según la tradición, puede predecir si su hija tendrá esposo o no, e incluso de qué edad será. Asimismo, para los tobas la edad del futuro marido o esposa se relaciona también con Luna, pues si se mira el cielo y la luna está bien madura la esposa o el marido será viejo — se trata, una vez más, de una de las tantas consecuencias que puede tener observar el cielo: "Luna nueva miraba a toda la gente y cuando está vieja, o alto, no hay que mirarla porque sino uno se casa muy viejo".

Entre los tobas, recordar las lunas en las que cada mujer tiene su período es, pues, un hecho considerado de gran importancia. Actualmente algunas mujeres también utilizan el calendario occidental, gregoriano, pero en general saben en qué fase lunar tendrán su período. Por otra parte, si a una mujer joven deja de tener su menstruación, comienza a "contar las lunas" pues es muy probable que esté embarazada. Una de las mujeres explicaba que quienes ahora son más grandes, sobre todo, cuentan las lunas para saber si están embarazadas. Antiguamente, cuando quedaban embarazadas, aquello que tenían más en cuenta "es la luna". Si pasaban dos lunas y no llegaba su menstruación, sabía por "su luna" si es que estaba encinta aunque "no sabe de fechas" o "de meses". Así, las tobas comienzan a contar las lunas para saber cuándo nacerá su hijo: "onolek a'wogoyk (una luna), dohol'ka a'wogoyka (dos lunas), treshol'ka a'wogoyk (tres lunas), etc.". Hoy en día son muchas las tobas que van al centro de salud, "la salita”, para ser atendidas por el asistente sanitario. Una de ellas cuenta que este les pregunta: “Na'yeta aga?'me a'wogoyk qahol'ha na'yak (¿hace cuántos meses [lunas] que vos no menstruás ya?), y las mujeres grandes dicen dohol'ka a'wogoyka (dos lunas). [...] Quiere decir que quedó embarazada. [...] Ahora nosotros decimos en castellano los meses. Hasta hoy día las mujeres grandes usan: a'woGoyk".

Es frecuente escuchar, tanto por parte de hombres como de mujeres de diversas edades, que si una mujer está embarazada de una niña la tendrá a los siete u ocho meses, pero que si es un varón nacerá a los nueve meses: "Cuando es mujer dice que nacen a los siete meses, sietemesinos, viste; cuando es varoncito ya es nueve". De esto se desprende que las mujeres, aunque no tuvieran noción de una duración exacta, sí tenían conocimientos que les permitían saber aproximadamente la cantidad de lunaciones tras la cual nacería el niño; de esta forma, la medición del tiempo es vivenciada pragmáticamente. 
Según la tradición toba, Luna es el responsable de la conformación mítica de la feminidad. En efecto, Luna es el primer hombre de todas las mujeres: "Así es la historia de la luna [...] Como que la luna me violó, pero es la forma de hablar de ellos". Es sólo por medio de un acto sexual con un personaje celeste que se da la conformación mítica de la feminidad. A este respecto, resulta interesante analizar etimológicamente la palabra misma que designa a la luna:

\begin{tabular}{|l|c|l|}
\hline a'woGoyk \\
\hline awoGo & $\mathrm{y}$ & $\mathrm{k}$ \\
\hline tener relaciones & pers. & masc. \\
\hline \multicolumn{2}{|l|}{ el que tiene relaciones sexuales } \\
\hline
\end{tabular}

La etimología refleja aquello que el mito escenifica: como dice uno de los ancianos tobas, que Luna "tiene un trabajo en el mundo" ocupándose de "hacer" a las mujeres al ser el primero que tiene relaciones sexuales con ellas, y por ende provocándoles su primera menstruación: “...él tiene muchas mujeres [...] Luna hace a la mujer que le viene la sangre, neta'gae (menarca)". Como señalan los tobas, los hombres sólo podrán estar con las mujeres luego de que Luna haya hecho su "trabajo".

Una jovencita relata que, cuando tuvo su primera menstruación, lloró mucho y se asustó, pero finalmente su madre le contó que el primer esposo de todas las mujeres es la luna, lo cual es parte del "estudio" al que suele hacerse referencia a la hora de hablar de los ritos de iniciación, y en el que se irán formando las "nuevas" mujeres (Córdoba 2008b). Así explican los tobas la aparición de la sangre, lo que provoca que la niña se transforme en mujer y que sea necesario prepararla para ese evento. Antes de esta etapa, se puede observar a niñas y niños pequeños jugando juntos, aunque a veces también lo hacen divididos según el sexo y en otras ocasiones por grupos de edad; luego de la primera menstruación, en cambio, la división de los sexos resulta más marcada socialmente.

La formación de la mujer es una tarea continua que comienza tempranamente, juego a juego, palabra a palabra, durante el proceso de socialización femenina ${ }^{11}$. Desde niñas observan atentamente a la madre, van aprendiendo con ella y poco a poco se ocupan de algunas tareas domésticas. Es muy común ver a las niñas llevando agua hasta su vivienda en compañía de su madre o junto a sus hermanas. A esta labor hay que agregar la recolección y carga de frutos de monte, la búsqueda de leña ${ }^{12}$, la preparación de comidas y el barrido de excremento de animales de los alrededores de la casa. En el monte las muchachas también aprenden a recolectar frutos y cortezas que sirven para obtener tintura; luego, con estas materias primas, aprenden las técnicas de hilado y 
de tejido, primero mirando y participando luego. Así, Córdoba (2008b) analiza el tema del tejido como elemento fundamental del proceso ritual de "construcción" de la mujer entre los tobas. Sin embargo, naturalmente cada familia confiere más peso específico a una u otra de estas actividades. En algunos casos, por ejemplo, se le otorga más relevancia al tejido de artesanías; una de las razones es que una ONG lleva a cabo actualmente un proyecto de desarrollo que incentivó la comercialización de los productos textiles. Sin embargo, no es la única tarea de las jovencitas, que buscan agua y todavía contribuyen con la recolección de frutos del monte para consumo del grupo doméstico. Es de destacar que los frutos de monte buscados por las mujeres proporcionan una buena parte de la alimentación durante ciertos períodos estacionales, por lo cual la participación de las jóvenes en la economía doméstica no es en absoluto una tarea secundaria ${ }^{13}$.

Métraux y otros autores que trabajaron con grupos cercanos a los tobas durante las primeras décadas del siglo XX observaron que las niñas realizaban estas tareas junto con sus madres (1946: 321). Al igual que Métraux, Nordenskiöld indica que las niñas chulupí-nivaclé aprenden sus futuras tareas jugando; de esa forma, cuando una madre busca agua con su niña, llena su cántaro al igual que el más pequeño que lleva consigo su hija (Nordenskiöld 2002: 60). Sin embargo, como apunta Córdoba (2008b), el aprendizaje cotidiano de saberes específicos resulta, por lo general, una de las cuestiones más relegadas analítica y descriptivamente al momento de la realización de esas primeras etnografías, que se centraban fundamentalmente en los mitos y los ritos inmediatamente asociables con la formación de la mujer. La feminidad se va conformando cotidianamente, y la primera menstruación que provoca Luna marca con nitidez una distinción claramente destacada en lo conceptual por los tobas. A nivel social no se trata de un acontecimiento más. La niña no sólo ha adquirido todos los conocimientos necesarios, sino que socialmente es reconocida como una mujer desposable. Todo lo que se transmite en este momento está sostenido por los aprendizajes anteriores, e intenta propiciar aptitudes en las mujeres entre las que se destaca la fortaleza. Es en ese momento, precisamente, cuando las muchachas terminan de recibir aquello que generalmente se denomina "Ios estudios". Una anciana explicaba que, antiguamente, una joven debía cumplir ciertos rituales que hoy día no son tan estrictos ${ }^{14}$. Una de las primeras resoluciones que se tomaban era apartarla de la vida social cotidiana: se la encerraba en una habitación a solas, sin luz, apartada de la casa. Únicamente podía acercarse a ella una anciana que la cuidaba y le llevaba algo de comida, acercándole el tejido para que trabajase. Allí dentro, según se reporta, la joven solía permanecer con la cabeza cubierta. Métraux (1937) agrega a este testimonio que el único momento en el que podía salir la joven era por la noche, para satisfacer sus necesidades naturales. Uno de los objetivos de este encierro era hacerla fuerte; también era por eso que se le daba muy poco alimento. Según las tobas, durante el encierro debían estar en una "cama" y quedarse bien derechas, luego de la reclusión eran bajadas del lecho para que "no les creciera la panza". Además, casi no se les daba de comer y había alimentos, como el pescado, que estaban absolutamente vedados. Otra de las prohibiciones consistía en evitar acercarse a los pozos de agua. Pasado el período menstrual, se las llevaba muy temprano hasta el río para que se bañaran y "para aprender las cosas para toda la vida, para ser bien trabajadora y ágil con los trabajos de la casa y con las tareas que debe realizar". Esta separación del entorno social cotidiano duraba lo que su primer 
ciclo: al terminar la instancia de reclusión, que también se repetía durante su segundo período, la joven era presentada ante todos como una mujer casadera. En algunas ocasiones, al terminar esta fase, se realizaba una fiesta en la que se invitaba al resto del grupo, se bailaba, se bebían grandes cantidades de aloja y se tocaban los instrumentos musicales tradicionales. Métraux (1937) explica que esto último sucedía, particularmente, cuando se trataba de la hija de un hombre importante en el grupo.

Aunque hay muchas de estas prescripciones rituales tradicionales que ya no se cumplen, a las jóvenes que menstrúan por primera vez se las sigue apartando de la vida social ordinaria: tal vez ya no se tomen medidas como taparles la cabeza, pero hay ciertos tabúes que se siguen cumpliendo y en algunos casos su quebrantamiento sigue provocando, al menos, dudas, resquemores e inquietudes culturalmente pautadas. En un artículo reciente, Gómez (2006) afirma que hay jóvenes que no avisan de que han tenido su primera menstruación para que no se las encierre. Lo anterior se liga, sin duda, con un proceso mayor de cambio que están teniendo estas comunidades desde principios del siglo XX y que aún hoy persiste; en este contexto, a los saberes tradicionales se añaden las enseñanzas proporcionadas tanto por organismos gubernamentales de salud, como por las ONGs que trabajan allí con diversos proyectos de desarrollo. Esto no implica que los nuevos conocimientos invaliden los anteriores, por más que estos, discursivamente, sean englobados dentro de aquello "que pertenece al pasado", sino que se generan intercambios de sentido entre las diversas esferas de conocimiento, tal como afirma Córdoba (2008b) en su estudio de los cambios y continuidades en los ritos femeninos de iniciación tobas.

\section{LAS MUJERES Y LA SANGRE}

Los datos tobas ofrecen pistas para repensar la "hematología" comparada que propone Belaúnde (2006: 206207) en su análisis de las relaciones entre sangre, género y cosmología. La primera vez que una mujer tiene su menstruación se denomina neta'gae. La segunda menstruación también puede ser objeto de cuidados especiales, y se denomina no'Gop chogo'te, en tanto que al resto de los períodos “normales" se los denomina na'yak. Durante los lapsos en los cuales una mujer tiene su menstruación, parecen exacerbarse las potencialidades intrínsecas de la feminidad. Si no se adhiere a los mandatos sociales, en efecto, los efectos del quebrantamiento de las reglas pueden llegar a desbordar a las mujeres menstruantes, provocando desgracias tanto para ellas mismas como para el resto del grupo doméstico e, incluso, la comunidad entera. Lo mismo apunta Métraux, que visitó a los tobas durante los primeros años de la década de 1930 (1937: 190-192). Durante nuestro trabajo de campo, el tema fue abordado en varias ocasiones y las respuestas coincidieron: cuando la mujer tiene su período debe restringir su dieta y no acercarse al río o a los pozos de agua. Amelia, una mujer de alrededor de 25 años, decía, por ejemplo, que ahora no se cuida mucho, pero al terminar su relato expresó temor ante el quebrantamiento de las prohibiciones que le enseñó su abuela. Cuando tuvo su primera menstruación "[tenía que estar] sentadita, no me dejan tomar mate, ni salir afuera". Debía quedarse en su cama hasta que terminara su período. Si no cumplía con el confinamiento, podía generar problemas a todos con wo'sak (el arco iris), una víbora muy grande que podría 
seguirla por medio de su olfato hasta su casa para atacarla e intentar llevarla al "otro lado, debajo de la tierra". No debía, tampoco, acercarse a ningún pozo de agua, porque podría llegar a sucederle que se levantara un viento muy fuerte y se desataran grandes lluvias ${ }^{15}$. La única forma de contrarrestar estos incidentes es por medio de la acción de un piogo'nak (chamán). Este es uno de los temas fundamentales de las historias que se aprenden y forman parte de los "estudios" que les legan las mujeres mayores a sus nietas e hijas. Algo que también deben aprender las muchachas es que, cuando están con su menstruación, no pueden comer ciertos alimentos como la miel y el pescado: si lo hicieran, los hombres que cazan o pescan nunca más tendrán resultados positivos. Durante su relato, Amelia decía que ya no se cuidaba mucho, relegando al pasado ciertos tabúes como "cuentos de los antepasados" que hoy cayeron en desuso. Sin embargo, luego expresó tener mucho temor al romper las reglas y hacer caso omiso de "los estudios" que le legaron las abuelas, diciendo que cuando tiene su período la invade el miedo. En efecto, le inquieta pensar que al ir a nadar podrá entrarle por su vagina la víbora asociada al agua, que puede matarla como en los cuentos de las abuelas. Por eso, concluye diciendo “...por eso yo tengo terror hasta hoy en día, porque mi abuela me contó así. Por eso, cuando yo tengo menstruación, a las cuatro de la tarde me lavo, me baño y me encierro: no salgo, tengo miedo, me da de ese miedo que me dio en ese cuento mi abuela". Como se expresó anteriormente, el wo'sak (lit. "arco iris") es un ser serpentiforme que huele de inmediato la sangre de aquella mujer que no se encerró (ni'tak Pa'me año'le), está relacionado con los animales anfibios, merodea cerca del agua pero puede moverse sin dificultad por el cielo y la tierra.

Tal como se trasluce en este tipo de argumentos, la creencia tradicional es que cuando una mujer tiene su menstruación debe encerrarse, no comer carne, pescado, miel ni tomar mate. En ese estado una mujer se torna muy peligrosa y se exacerban sus potencialidades latentes, aquellas que la asocian al ámbito celeste y que la vuelven capaz de desatar desgracias a nivel individual, familiar y/o grupal; en cualquiera de los casos los informantes señalan que "es culpa de ella" porque "es el significado de la menstruación: el significado de las mujeres de la menstruación". Por ejemplo, si comiera pescado o carne provocaría que el hombre que la provee no pueda pescar o cazar más; tanto hombres como mujeres coinciden en ello. Si una mujer come mucho, puede ponerse "barrigona", y una mujer toba debe ser "guapa", fuerte y saludable para proseguir con sus tareas cotidianas. Asimismo, uno de los peligros más temidos se relaciona a la nombrada serpiente arco iris (wo'sak), también llamada, na'naik 'poleo (lit. "serpiente grande").

Es interesante que el desencadenante de la menarca sea Luna, el héroe celeste que baja a la tierra para desposar mujeres. Al transformarse en su "primer esposo", se trata del personaje mítico que tiene a cargo la tarea de "completar" o "sellar" la formación de esta primera etapa social femenina. Para ser tales, las mujeres deben relacionarse con el cielo, con los ciclos y con los movimientos que son propios de la luna. Los movimientos aparentes de la luna indican, pues, cuestiones de orden tanto simbólico como práctico, y una de ellas es que su posición indica en qué momento la mujer va a tener su menstruación, ayudando a saber si está embarazada. Pero esta no es la única situación en la que se relaciona a las mujeres con el plano celeste, pues el cielo es el lugar de origen mítico de las mujeres. 


\section{LAS ESTRELLAS Y EL ORIGEN MÍTICO DE LAS MUJERES}

Durante una de las noches en las que trabajábamos junto a un fogón, observando el cielo e identificando estrellas específicas, uno de los tobas me relató el mito del advenimiento de las mujeres. Como en otras cosmologías chaqueñas, el origen mitológico de las mujeres tobas es pues eminentemente estelar; se trata de seres que venían desde el cielo (pi'yem) hasta la tierra (a'lewa) para alimentarse, y que se quedaron aquí por la acción de los hombres/animales primigenios ${ }^{16}$. Los seres primigenios iban a cazar, llevaban lo que habían conseguido al campamento y ahí lo dejaban; cuando ellos se retiraban, las mujeres descendían del cielo, se lo comían y regresaban. Como los hombres querían saber quién les había robado su comida, dejaron un cuidador. El primero de ellos fue el loro. El ave vio bajar a las mujeres y mientras ellas estaban allí les tiraba hojas del árbol una y otra vez. Las mujeres se dieron cuenta de que había alguien más y, al encontrarlo, lo dejaron mudo; por eso, cuando los hombres regresaron al campamento, el loro no les pudo contar lo sucedido. Finalmente, decidió quedarse el jefe para vigilar el campamento. Wo'le $e^{17}$ divisó a las mujeres, cortó la cadena por la que bajaban y ellas cayeron a la tierra quedando allí. Al principio, el jefe intentó bajar a las mujeres que estaban más arriba, que eran más blancas, pero no podía. Luego del fallido intento de quedarse con las mujeres más cercanas al cielo, y para no perder tiempo, tiró su hierro hacia el resto de la cadena, donde estaban aquellas que finalmente cayeron a la tierra. Wo'le llamó a todos aquellos que habían ido a buscar alimentos. Avisados por el jefe, cada uno de ellos cavó en la tierra hasta encontrar alguna de las mujeres y adoptarla como esposa; el jefe, así, ya tenía dos esposas ${ }^{18}$. Pero los hombres primigenios no podían tener relaciones sexuales con las mujeres porque ellas tenían dientes en la vagina y también comían por allí; de hecho, uno de los entrevistados relató que una de ellas llegó a comerse a un hombre, mientras que otros explicaron que lo ingerido fueron sus órganos genitales. Pero hubo uno de los hombres/animales, wayaka'lachigi, el zorro, que tenía conocimiento de esta segunda boca, y con una piedra rompió los dientes de todas las vaginas dentadas ${ }^{19}$. A partir de ese momento, los hombres pudieron tener relaciones sexuales con las mujeres.

Las mujeres, en sus orígenes, son entonces seres celestes, que no quedaron en la tierra por voluntad propia. Tal como afirma Palmer (2005: 90) para el caso wichí, las mujeres debieron ser domesticadas, humanizadas: es por medio del zorro que el resto de los hombres acceden a tener relaciones sexuales con ellas. Así, finalmente, las mujeres pueden convertirse en esposas, se instaura el matrimonio y los hombres pueden comenzar a tener hijos con ellas. Miller (1977: 324) analiza una versión del mito perteneciente a otro grupo toba, concluyendo que al estar asociadas a muchos niveles cosmológicos, como el celeste y el terrestre, las mujeres son consideradas seres tan poderosos como peligrosos. En la versión aquí resumida, y en todas las que me fueron contadas durante mis estadías entre los toba, parte de las mujeres, las caracterizadas como "blancas" o "vestidas", lograron regresar al cielo, y aún son estrellas; en concordancia, la totalidad de las estrellas (waqachi' $\tilde{n} i^{20}$ ) son concebidas genéricamente como mujeres: ia'wo. 
A partir de su origen mítico, pues, las mujeres son catalogadas como seres peligrosos, ambiguos, asociados con el cielo pero obligadas a quedarse en la tierra. Las mujeres, en la perspectiva del mito, son seres liminales, poderosos. Las mujeres primigenias tienen una segunda boca, la vagina dentada, un órgano que caracteriza a las mujeres celestiales, y en la perspectiva toba pre-sociales: cuando el mito relata cómo wayaka'lachigi quiebra los dientes de esta boca, simboliza de algún modo la domesticación del enorme poder implícito en la sexualidad femenina. Puede deducirse que esa peligrosidad es un rasgo marcado en la representación cultural de la feminidad, lo cual coincide con la forma en que es concebido el cielo, lugar originario de las mujeres: en efecto, el cielo es descrito como un lugar frío, con fuegos que explotan y no calientan, poblado de seres que pueden bajar a la tierra y con quienes es mejor no encontrarse; en suma, un espacio poco apto para la vida humana.

\section{PALABRAS FINALES}

Escribe Lévi-Strauss: “Del sol y la luna puede decirse la misma cosa que de los innumerables seres naturales que manipula el pensamiento mítico: no trata de darles un sentido; se significa por ellos" (1986: 211). Los significados simbólicos enlazados con las estrellas (waqachi'ñi) y la luna (a'wogoyk) expresan de forma codificada las prescripciones y mandatos sociales relacionados con la mujer. Esta estructura corresponde a un entramado simbólico que, lejos de acotarse a un plano representacional, se liga con regulaciones sociales, con técnicas corporales "hechas carne" en la forma de actuar de las mujeres, en su actitud corporal, en su tono de voz e incluso en las sonrisas que suelen esconderse detrás de sus manos: una feminidad contenida, vergonzosa, oculta, que constantemente evita el desborde ${ }^{21}$.

Como seres terrestres, el deber de las mujeres consiste en intentar alcanzar el estereotipo social de feminidad, sacando adelante a su familia y realizando las tareas que les son culturalmente conferidas. Por otra parte, regulando su sangrado, las mujeres tobas se ocupan de canalizar su peligrosidad orgánica, imponiendo límites al "poder" que les es intrínseco y que fuera de sus cauces sociales podría provocar desgracias personales, familiares o comunitarias. La mayor parte de las entrevistadas afirman cumplir en algún grado con las interdicciones sociales que, en líneas generales, todavía provocan respeto y que por lo menos generan alguna duda cuando son quebrantadas. Cuidándose a sí misma, al fin y al cabo, la mujer cuida a todos: este parece ser el punto nodal de la ideología asociada con la luna y los ciclos vitales femeninos. Ciertas claves simbólicas condensadas en los mitos parecen prestar sentido a una serie de prácticas que procuran canalizar, limitar y encauzar debidamente una potencia femenina de otra forma temible debido a su origen extrahumano. Se trata de un trabajo simbólico que genera prescripciones, normas y valoraciones que reglamentan la praxis cotidiana; de un trabajo que delinea simbólicamente los contornos de una ideología que condiciona la operación de un determinado orden social, en el cual la tarea masculina es justamente administrar el poder latente en la fecundidad femenina (Héritier 1996: 220-228). Al fin y al cabo, la menstruación no es un mero proceso orgánico que ocurre "naturalmente": es un suceso producido por los otros, mediante la manipulación externa de la genitalidad femenina (Belaúnde 2006: 
217). En efecto, míticamente la mujer es un ser celestial que sólo gracias a la acción de wayaka'lachigi (el zorro), y posteriormente al "trabajo" de Luna, puede permanecer con los hombres reproduciendo la sociedad. Pero en el plano narrativo sigue siendo un ser de origen celeste, que para estar en la tierra sin generar inconvenientes debe cumplir con determinadas prescripciones. Sobre todo, las mujeres deben cuidarse y contenerse en el momento en el cual se vuelven extremadamente peligrosas por activarse sus facultades "pre-sociales".

Sin embargo, la relación entre las mujeres y el cielo no se limita a su origen mítico. La feminidad vuelve a entrar en relación con lo celeste a la hora de la transformación de las muchachas en mujeres. Una vez más, esta instancia crítica marca la aparición de Luna: para que las mujeres puedan relacionarse como tales con los hombres, es necesario que haya una nueva intermediación celeste, que repita la actuación decisiva del trickster en el tiempo inmemorial. Por medio de Luna, en efecto, se posibilita la continuidad de la sociedad: las mujeres se casarán, serán madres y posteriormente abuelas encargadas de brindar los "estudios" a su descendencia femenina - es decir, crear nuevas mujeres.

Siguiendo la intuición lévi-straussiana, es posible postular que la luna y sus ciclos ofrecen un medio concreto a los tobas para concebir colectivamente ciertos procesos abstractos como los ciclos femeninos, la reproducción, la división sexual del trabajo, las relaciones de género y aquellos períodos temporales más breves que las grandes estaciones que, no obstante, asumen una importancia decisiva en el ciclo anual. Para las mujeres, en efecto, las consecuencias de la asociación con Luna son bastante concretas: la diferencia entre la vida de la niña y la de la adulta casadera, así como también la consecuente reconfiguración de los roles sociales del resto de los individuos con respecto a ella - así, muchos hombres con los que antes jugaban se convierten en potenciales esposos. Luna, de ese modo, imprime su sello a las mujeres para toda la vida, pues aunque lleguen a su menopausia, siempre recuerdan "su" luna: "Cuando mi mamá dejó de menstruar ella no se olvida su luna". El satélite opera pues como un marcador simbólico que codifica una lectura concreta de la temporalidad, materializada en facetas de la vida individual, conyugal y social como también en las prescripciones sociales ligadas culturalmente con la feminidad, o bien con la definición “orgánica” de embarazos, precauciones y períodos en los cuales la mujer debe cuidarse para no generar desgracias a sí misma o al grupo. La ideología asociada con las imágenes lunares codifica una suerte de reflexión colectiva sobre el origen liminar, peligroso, ambiguo de las mujeres, la menstruación y la periodicidad, que necesitan ser "domesticadas" para que los hombres puedan tener esposa e hijos y la sociedad se reproduzca. 


\section{NOTAS}

1 Agradezco al Dr. Diego Villar y a los dos comentaristas anónimos de Campos los comentarios realizados a una primera versión de este trabajo.

2 Este trabajo forma parte de una investigación más amplia sobre las concepciones etno-astronómicas de las sociedades indígenas chaqueñas, algunos de cuyos resultados pueden apreciarse en Gómez y Braunstein 2004; Gómez 2007, 2008a, 2008b, 2008c. Dicha investigación fue financiada gracias a una beca doctoral CONICET (2005-2009).

3 Este conjunto, en particular, reúne a los grupos que hablan lenguas pertenecientes a los troncos lingüísticos Mataco-Maká (wichí, nivaclé, chorote, maká), Guaycurú (toba, pilagá, mocoví, mbayá-caduveo) y los Maskoi (lengua, sanapaná, angaité, toba-lengua y guaná-lengua). Según el mismo criterio clasificatorio, los grupos "atípicos" serían entonces los "norteños", de lengua Zamuko (ayoreo y chamacoco), y los "occidentales", hablantes de diversas lenguas de origen Tupí-Guaraní (chiriguano, chané, tapiete, simba, guaraní occidental) (Braunstein 2008).

4 En los alrededores de la ciudad de Ingeniero Juárez, por ejemplo, hay un importante núcleo poblacional Ilamado "Barrio Toba" en donde se asienta gente que suele emparentarse con los tobas que viven en las comunidades antes nombradas, pero que han llegado a residir más cerca de la ciudad.

5 Todas las traducciones del inglés son nuestras.

6 "Bóveda celeste" es el término astronómico utilizado para referirse al cielo a partir de observaciones realizadas desde la tierra. A partir de la perspectiva brindada por un observador terrestre, el cielo es como una inmensa bóveda transparente en la que pueden divisarse estrellas que parecen estar "dibujadas" allí. Esta gran esfera cubriría el imaginario "disco plano" que parece conformar la tierra para un observador ubicado en la misma. Por otra parte, el "horizonte" sería la zona conformada por la parte más extrema del disco imaginario terrestre, allí donde parece ocurrir un contacto entre la esfera celeste y la tierra. El punto más alto de esta bóveda es llamado "cenit", y su opuesto "nadir" (Aveni 1993).

7 Por razones de confidencialidad, de aquí en adelante, cuando se nombre individualmente a un toba, será por medio de un seudónimo.

8 En otros grupos de las tierras bajas sudamericanas — como los guaraníes del Paraná, los arawak de las Guyanas, los waraos del Orinoco, los ticunas de la Amazonía occidental, los aguarunas y los shipibos del Perú o bien los cunas de Panamá- las manchas de la luna suelen explicarse por medio del mito que habla de las relaciones incestuosas entre Luna, personaje masculino de origen celeste, y su hermana, o en otras versiones su tía o su abuela. Para una descripción de estos mitos, ver Blixen (1992). Para una teoría panamazónica sobre el llamado "incesto de Luna", véase Belaúnde (2005).

9 Tola (2001: 77) sugiere que, entre los tobas orientales, la primera menstruación es provocada por Luna por medio de su mirada y no de un acto sexual. Entre los cercanos wichí del Chaco, en cambio, un mito explica que la luna es un hombre apuesto que vivía en la tierra y que cada vez que tenía relaciones sexuales con las mujeres, estas morían; eso sucedía porque Luna las desgarraba con su pene, que era desmesuradamente largo. Finalmente Luna tiene relaciones sexuales con otra jovencita pero trata de ser cuidadoso: la muchacha tuvo una hemorragia pero logró sobrevivir y se curó; así se explica el origen de la menstruación. En otras versiones, Luna desflora a su nieta (Blixen 1992: 20-21).

10 Ya'kachi fue traducido como "muy viejo", "muy anciano". En el vocabulario de Tebboth (1943: 214), yagáic: adulto, pubertad, varón // áchigui: anciano, decrépito, envejecer, vejez, viejo.

11 Existen algunos trabajos actualizados sobre la conformación de la mujer y las representaciones que corresponden a la menarca y a la menstruación entre los toba del oeste formoseño (Gómez, M. 2006, Córdoba 2008b). Con respecto a otros grupos chaqueños, ver por ejemplo Idoyaga Molina (1976/77), Dasso (1992), Tola (2001), Palmer (2005) y Citro (2008).

12 Las mujeres siguen buscando y llevando leña hasta el hogar, aunque actualmente también puede verse a algunos hombres haciéndolo en sus bicicletas. Según Arenas (2003: 144) esta actividad, junto con la de traer agua de la represa, es llevada a cabo por varones y no es catalogada como vergonzosa pese a ser tradicionalmente reputada como femenina. 
13 Aunque actualmente hay un acceso generalizado al consumo de alimentos envasados, los productos recolectados en el monte siguen estando presentes en la dieta general, variando en su importancia según la disponibilidad estacional (Arenas 2003, Valeggia, Lanza y Córdoba 2005).

14 Para una descripción de los rituales tradicionales de iniciación, véase Métraux (1937: 190-192).

15 En otras versiones las grandes lluvias pueden desencadenar inundaciones que en algunos casos llegan a destruir la comunidad (Métraux 1946: 29-30). Para un catálogo de los peligros individuales y colectivos asociados al sangrado en la Amazonía indígena, véase Belaúnde (2006: 228).

16 Para otras versiones de este mito en este y otros grupos, ver Karsten (1923: 104-106), Lehmann- Nitsche (1924: 284-285), Métraux (1946: 102-107), Cordeu (1969/70: 143-148), Palavecino (1969/70: 185-186), Miller (1977: 323-325), Wilbert y Simoneau (1982a: 67-77; 1982b: 101-143; 1985: 29-38; 1989: 130-155), Pérez Diez (1983: 134-169), Idoyaga Molina (1986: 165-174), Barúa y Dasso (1999:253257) y Palmer (2005).

17 Este personaje es caracterizado por los tobas como un águila negra. En el mito registrado por Métraux (1946: 100-103), se dice, en cambio, que esta ave es un "halcón". Por otra parte, debe tenerse en cuenta que los animales que se nombran en este relato son hombres/animales que habitaban el mundo primigenio, es decir, figuras que según el registro aparecen ya sea como hombres o bien como animales.

18 Este acontecimiento bien podría ponerse en relación con la costumbre tradicional de la poliginia de los líderes: Métraux (1937: 384385), por ejemplo, explica que un jefe podía tener más de una esposa, pero que esa costumbre también le estaba permitida a cualquier otro indígena. El análisis preliminar de las redes genealógicas contemporáneas, de modo similar, permite corroborar todavía algunos casos de poliginia entre los tobas de Vaca Perdida, Rinconada y Barrio Toba (Lorena Córdoba, comunicación personal).

19 En otras de las versiones, este acto fue llevado a cabo mediante un duro trozo de madera de palosanto (Bulnesia samientoi).

20 Waqachi'ñi (estrella) es el nombre genérico dado a todos aquellos astros que no tienen algún nombre que los distinga del resto. En esta generalización no caben los asterismos; de hecho, por lo menos uno de ellos (Dapi' chi) es considerado un hombre antiguo.

21 Una excepción parecerían ser las peleas que se producen entre mujeres por cuestiones amorosas. Se trata de peleas por los hombres que suceden hoy y que atestiguan hace décadas los reportes tanto de Métraux (1937: 385-386) como también de los misioneros anglicanos (Leake 1933: 114-116). 
ARENAS, Pastor. 2003. Etnografía y alimentación entre los toba-ñachilamoleek y wichí-Ihuku'tas del Chaco Central (Argentina). Buenos Aires: Dunken.

AVENI, Anthony F. 1993. Observadores del cielo en el México Antiguo. México: Fondo de Cultura Económica.

BARÚA, Guadalupe \& DASSO, María Cristina. 1999. "El papel femenino en la hostilidad wichí". In M. Califano \& M. C. Dasso (eds.) El chamán wichí. Buenos Aires: Ciudad Argentina.

BELAÚNDE, Luisa Elvira. 2005. El recuerdo de Luna. Género, sangre y memoria entre los pueblos amazónicos. Lima: Fondo Editorial UNMSM.

2006. "A força dos pensamentos, o fedor do sangue. Hematologia e gênero na Amazônia". Revista de Antropologia 49(1): 205-243.

BLIXEN, Olaf. 1992. “Las manchas de la luna y sus explicaciones míticas en Sudamérica”. MOANA 4(2): 1-41.

BRAUNSTEIN, José. 2008. “Muchos caciques y pocos indios. Conceptos y categorías del liderazgo indígena chaqueño". In J. Braunstein \& N. Meichtry (eds.) Liderazgo, representatividad y control social en el Gran Chaco. Corrientes: Editorial Universitaria de la Universidad Nacional del Nordeste.

CITRO, Silvia. 2008. “Creando una mujer: ritual de iniciación femenina y matriz simbólica de los géneros entre los tobas takshik". In S. Hirsch (coord.) Mujeres indígenas en la Argentina. Cuerpo, trabajo y poder. Buenos Aires: Biblos.

CORDEU, Edgardo. 1969/70. “Aproximación al horizonte mítico de los tobas". Runa 12(1/2): 67-173.

CÓRDOBA, Lorena. 2008. “Liderazgo, grupos locales y organización sociopolítica entre los toba del Oeste formoseño". In J. Braunstein y N. Meichtry (eds.) Liderazgo, representatividad y control social en el Gran Chaco. Corrientes: Editorial Universitaria de la Universidad Nacional del Nordeste.

2008. “¿Existe la iniciación? Procesos de construcción social de la feminidad entre los toba del oeste formoseño". Acta Americana 16(2):61-83.

DASSO, María Cristina. 1992. “Algunas observaciones acerca del Lewó entre los Wichí". Mitológicas 7: 27-35.

GÓMEZ, Cecilia. 2007. “Kates Ihukwetah. La representación social, material y estelar de la mujer entre los Wichí”. Acta Americana 15(2): 97-116.

2008. "Venus and the Star Woman". Archaeologia Baltica 10: 25-28.

2008. “Na'gaiq, lakawa' hegen y dapi'chi. Huellas de una zona de frontera en dos representaciones celestes toba-pilagá". Estudios Latinoamericanos 28: 185-209.

2008. “Parentesco y representación estelar de la mujer entre los Wichí del Gran Chaco". In Actas de/ V/ Congreso de Americanistas. Buenos Aires: Dunken. 
\& José BRAUNSTEIN. 2004 "Algunas representaciones astronómicas en las culturas tradicionales del Gran Chaco". In Actas del XXIV Congreso de Geohistoria Regional. Resistencia: Instituto de Investigaciones Geohistóricas.

GÓMEZ, Mariana. 2006. “Representaciones y prácticas en torno a la menstruación y menarca entre mujeres tobas: entre la salud de las mujeres y la construcción social del género femenino". Papeles de trabajo 14: 9-51. GORDILLO, Gastón. 2005. Nosotros vamos a estar acá para siempre. Historias tobas. Buenos Aires: Biblos. HÉRITIER, Francoise. 1996. Masculino/Femenino. El pensamiento de la diferencia. Barcelona: Ariel.

IDOYAGA MOLINA, Anatilde. 1976/77. “Aproximación hermenéutica a las nociones de concepción, gravidez y alumbramiento entre los pilagá del Chaco Central". Scripta Ethnologica 4: 78-98.

1986. "Estudio fenomenológico del mito de origen de las mujeres entre los pilagá (Chaco Central)". Anales de arqueología y etnología 41/42: 165-174.

KARSTEN, Rafael. 1923. The toba indians of the Gran Chaco. Helsingfors: Åbo Akademi.

LEAKE, Alfred. 1933. "The Story of the Toba Mission". The Magazine of the South American Missionary Society 66: 67-69.

LEHMANN-NITSCHE, Roberto. 1924. “La Astronomía de los Tobas”. Revista del Museo de La Plata 27: $267-285$.

LÉVI-STRAUSS, Claude. 1986. “El sexo de los astros". In Antropología estructural II. Madrid: Siglo Veintiuno Editores.

1997. Mitológicas III. El origen de las maneras de mesa. México: Siglo XXI Editores.

MÉTRAUX, Alfred. 1937. “Études d’Ethnographie Toba-Pilagá (Gran Chaco)”. Anthropos 32: 171-194, 378-401.

1946. Myths of the Toba and Pilagá Indians of the Gran Chaco. Memoirs of the American Folklore Society 40. Philadelphia: The Waverly Press.

MILLER, Elmer. 1977. "Simbolismo, conceptos de poder y cambio cultural de los tobas del Chaco argentino". In E. Hermitte (ed.) Procesos de articulación social. Buenos Aires: Amorrortu.

NORDENSKIÖLD, Erland. 2002. La vida de los indios. El Gran Chaco (Sudamérica). La Paz: Editorial APCOB.

PALAVECINO, Enrique. 1969/70. “Mitos de los indios tobas". Runa 12(1/2): 177-197.

PALMER, John. 2005. La buena voluntad wichí. Una espiritualidad indígena. Formosa y Salta: APCD y otros.

PEREZ DIEZ, Andrés. 1983. "A tale of the mataco about the origin of women". Latin American Indian Literatures 7(2): 134-169.

TEBBOTH, Tomás. 1943. “Diccionario Toba”. Revista del Instituto de Antropología de la Universidad Nacional del Tucumán 3(2): 35-221.

TOLA, Florencia. 2001. "La luna en el imaginario masculino y femenino de los tobas (qom) orientales del Chaco argentino". Ava 3: 75-88. 
VALEGGIA, Claudia, LANZA, Norberto \& CÓRDOBA, Lorena. 2005. “Fuentes de variación en la alimentación actual de los toba-pilagá del Oeste formoseño". In Actas del V Congreso de Americanistas. Vol. 2. Buenos Aires: Dunken.

WILBERT, Johannes \& SIMONEAU, Karin (eds.). 1982. Folk Literature of the Mataco Indians. UCLA Latin American Studies, 52. Los Angeles: UCLA Latin American Center Publications.

(eds.). 1982. Folk Literature of the Toba Indians. Volume One. UCLA Latin American Studies, 54. Los Angeles: UCLA Latin American Center Publications.

(eds.). 1985. Folk Literature of the Chorote Indians. UCLA Latin American Studies, 60. Los Angeles: UCLA Latin American Center Publications.

(eds.). 1989. Folk Literature of the Toba Indians. Volume Two. UCLA Latin American Studies, 68. Los Angeles:

UCLA Latin American Center Publications. 


\section{A lua e a feminilidade entre os Tobas do Oeste de Formosa (Grã-Chaco, Argentina)}

\section{RESUMO}

O presente trabalho aborda a estreita e significativa associação existente entre a mulher e o céu na cosmologia dos Tobas do Oeste de Formosa (família linguística Guaicuru). Para tanto, é focada a relação estabelecida, num nível prático e simbólico, entre o universo feminino e o personagem celeste, representado pela lua. A lua é um ser masculino que no plano narrativo deixa a sua marca na constituição mitológica da mulher toba. A partir desse ponto, é realizada uma analise do conjunto de mecanismos sociais e aspectos da organização social ligados à concepção toba da feminilidade. A análise da trama simbólica de relações significativas entre a feminilidade e o plano celeste mostra, por sua vez, que a mulher é considerada como um ser perigoso, com marcadas características de liminaridade. Em decorrência disso, a práxis social toba constrói uma feminilidade obediente às prescrições sociais, pois a insubordinação e a quebra das normas na vida cotidiana podem desencadear uma série de desajustes que vão do individual ao coletivo, podendo também gerar desordens cósmicas.

PALAVRAS-CHAVE: toba, lua, mulher, céu, Chaco.

\section{Feminity And The Moon Among The Toba Of Western Formosa (Gran Chaco, Argentina)}

\section{ABSTRACT}

This paper analyzes the meanings of the Toba cosmology regarding the association between women and the sky. It is described the symbolism and praxis in the relationship between the feminine universe and the mythical character portrayed by the Moon. In the narrative level, Moon is a male entity which conducts the mythological conformation of Toba woman. Regarding this point, the social mechanisms that contribute to the cultural conformation of women are analyzed. The analysis of this symbolic framework shows that, from the Toba point of view, women are dangerous entities, who display marked characteristics of liminality. This leads to the conclusion that the Toba society builds up a kind of femininity obedient to social requirements: insubordination and rule-breaking in everyday life may trigger a series of maladjustments, individual or collective, which can unchain even cosmic disorders.

KEYWORDS: toba, moon, woman, sky, Chaco.

Recebido em 9/04/2010 